\title{
Analisis Faktor-Faktor Fundamental Rasio Keuangan Terhadap Harga Saham
}

\author{
Neni Marlina Br Purba ${ }^{\mathrm{a},{ }^{*}}$ dan Handra Tipa ${ }^{\mathrm{b}}$ \\ aAkuntansi, Universitas Putera Batam,neni.marlina@puterabatam.ac.id, Indonesia \\ bAkuntansi, Universitas Putera Batam, Handra.tipa@puterabatam.ac.id, Indonesia
}

\begin{abstract}
This research is intended to understand how the Fundamental Factors of Financial ratios Against Share Prices in LQ45 Companies listed on the Indonesia Stock Exchange. Which includes fundamental factors, namely Return on Equity (ROE), Return on Asset (ROA), Debt to Equity Ratio (DER), Debt to Asset Ratio (DAR), Current Ratio (CR), Earning Per Share (EPS). All LQ45 companies listed on the Indonesia Stock Exchange (IDX) from 2014 to 2018 are the population. Samples were taken by determining criteria in accordance with the research objectives. The results of the data are then processed using the classical assumption test. Then the hypothesis is tested by multiple linear regression test, simultaneous test (F test), partial test ( $t$ test) and determination test (R2 test). Based on the test results with the help of SPSS, it is partially obtained fundamental factors which include Return on Equity (ROE) and Earning Per Share (EPS) have a significant effect on stock prices. Meanwhile, stock prices are affected but not significantly by Return on Assets (ROA), Debt to Asset Ratio (DAR), and Current Ratio (CR). Through a joint test, the stock price is also significantly influenced by all the variables included in the fundamental factors.
\end{abstract}

Keywords: Fundamentals, Financial ratios

*Corresponding author. E-mail: neni.marlina@puterabatam.ac.id 


\section{Pendahuluan}

Sebagai calon seorang investor, maka harus benarbenar memperhatikan perusahaan yang ingin dibeli sahamnya agar laba yang diharapkan dapat diperoleh dengan baik. Untuk itu para investor perlu memperhatikan faktor-faktor fundamental rasio keuangan suatu perusahaan salah satunya seperti rasio profitabilitas. Karena dengan Adanya ketidakstabilan dalam variabel fundamental dalam suatu perusahaan dapat menyebabkan adanya fluktuasi harga saham di pasar modal (Jiwandono, 2014). Secara internal kinerja perusahaan juga mempengaruhi naik-turunnya harga saham. Kinerja perusahaan tergambar dari bagimana laporan perusahaan yang dilaporkan dan hasil laporan keungan yang dilihat berdasarkan rasiorasio keungan fundamental tersebut (Anisa, 2015). Hal ini dapat disimpulkan bahwa faktor fundamental rasio keuangan dapat menentukan bagimana kinerja sebuah perusahaan dan resiko apa yang akan dapat dihadapi kedepan.

Rasio-rasio keuangan yang telah di-publish dapat menjadi gambaran kinerja perusahaan dalam periode tertentu. Hal ini akan menjadi panduan penanam saham untuk berinvestasi atau tidak diperusahaan. Jika rasio keungan yang dilaporkan kurang baik, maka akan menurunkan minat investor untuk membeli saham perusahaan dan harga saham perusahaan juga secara otomatis down (Suselo et al., 2015). Banyak terdapat rasio keuangan yang menjadi acuan untuk meramalkan harga saham antara lain Return on Equity (ROE), Return on Asset (ROA), Debt to Equity Ratio (DER), Debt to Asset Ratio (DAR), Current Ratio (CR), Earning Per Share (EPS), dan Book Value per Share (BVS) (Artha et al., 2014).

Rasio ini dapat dijadikan untuk menilai pergerakan harga saham atau bisa juga menilai nilai intrinsik perusahaan untuk melihat perbandingan harga saham dalam penentu membeli saham perusahaan. Faktor fundamental yang berubah dapat disebabkan karena rasio keuangan yang tidak menentu juga, jika rasio tersebut tidak dapat di prediksi maka akan memberikan dampak yang tidak baik terhadap minat investor dalam memiliki saham perusahaan. Analisis investor yang baik melalui penghitungan rasio fundamental keuangan, dapat menjadi salah satu informasi yang penting dagi investor agar tidak rugi dalam berinvestasi (Julia \& Diyani, 2016).

Selain pertimbangan atau analisis laporan keuangan perusahaan, investor juga sangat penting dalam melihat prestasi perusahaan dalam Bursa Efek Indonesi, karena semakin tinggi nilai transaksi di pasar regular pada satu tahun terakhir maka kemungkinan pengembalian yang lebih tinggi akan diperoleh oleh investor (Suselo et al., 2015). Pemilihan yang dilakukan berdasarkan kriteriakriteria tertentu didalam memilih perusahaan yang terbaik di bursa efek indonesia maka terciptalah yang biasa kita sebut perusahaan LQ45.

Perusahaan yang telah memenuhi persyaratan atau kriteria pertimbangan kapitalisasi melalui pasar modal, perusahaan tersebut juga biasanya menjadi perusahaan yang melakukan transaksi yang paling banyak didalam jual-beli saham di pasar reguler dalam 12 bulan terakhir. Karena dianggap memiliki kredibilitas yang baik, sehingga banyak investor tertarik untuk menginvetasikan saham ke perusahaan tersebut dengan harapan pengembalian yang tinggi (Suselo et al., 2015). Meskipun perusahaan tersebut termasuk dalam perusahaan LQ45, tidak ada jaminan jika para investor pasti akan meraup pengembalian yang pasti atau tetap stabil. Tidak stabilnya hargaharga saham di LQ45 dapat digambarkan pada tabel 1.

Tabel 1

Harga Saham (dalam rupiah)

\begin{tabular}{cccccc}
\hline No. & $\begin{array}{c}\text { Kode } \\
\text { Emiten }\end{array}$ & $\mathbf{2 0 1 5}$ & $\mathbf{2 0 1 6}$ & $\mathbf{2 0 1 7}$ & $\mathbf{2 0 1 8}$ \\
\hline 1. & AKR & 7.175 & 6.000 & 6.350 & 4.290 \\
2. & BSDE & 1.800 & 1.755 & 1.700 & 1.255 \\
3. & CTRA & 1.451 & 1.335 & 1.185 & 1.010 \\
4. & EXCL & 3.600 & 2.310 & 2.960 & 1.980 \\
\hline
\end{tabular}

Sumber: www.idx.co.id

Fluktuasi atau perubahaan naik turun harga saham tersebut sangat dipengaruhi oleh faktor-faktor fundamental perusahaan seperti rasio profitailitas Return on Equity (ROE), Return on Asset (ROA), Debt to Equity Ratio (DER), Debt to Asset Ratio (DAR), Current Ratio (CR), Earning per Share (EPS) dan rasio-rasio keuangan lainnya. Semakin turun persentase nilai rasio keuangan ataupun profitabilitas perusahaan maka akan memungkinkan menurunnya harga saham di dalam pasar modal, hal ini dikarenakan minat investor terhadap perusahaan tersebut juga menurun. Perusahaan yang tidak diminati oleh investor secara otomatis harga sahamnya akan menurun pula (Artha et al., 2014). Melalui pemaparan masalah yang cukup mendalam diatas maka, peneliti ini bertujuan dalam menganalisis Faktor-Faktor Fundamental Rasio Keuangan Terhadap Harga Saham. 


\section{Kajian Pustaka}

\section{Harga Saham}

Berhasil atau tidaknya sebuah perusahaan didalam operasional perusahaan dapat dinilai dari tolok ukur harga saham perusahaan yang dijual di pasar modal. Semakin meningkat harga saham yang ditawarkan dapat mendorong keuntungan yang meningkat bagi pihak pemilik saham sehingga sangat menguntungkan bagi pihak investor dan juga perusahaan (Jiwandono, 2014). Tingginya permintaan atas penjualan saham dapat meningkatkan harga saham secara go public. Maka dapat dikatakan bahwa harga saham perusahaan sebagai gambaran umum kepada pemegang saham dan juga masyarakat keadaan perusahaan yang sedang terjadi (Egam et al., 2017).

\section{Return on Equity}

Rasio yang dihitung berdasarkan laba bersih terhadap modal biasa disebut dengan Return on Equity (ROE). Return on Equity (ROE) adalah jumlah laba bersih terhadap ekuitas perusahaan. Rasio ini diperlukan untuk mengukur kinerja perusahaan dalam penggunaan sumberdaya model yang dimiliki dalam meghasilkan laba yang maksimal bagi perusahaan (Julia \& Diyani, 2016).

\section{Return on Asset}

Aktivitas perusahaan yang dilakukan dan menghasilkan laba untuk perusahaan diukur dengan Return on Asset (ROA). Dengan kata lain, ROA juga dapat dijadikan indikator perusahaan untuk menghasilkan laba atas aseet yang dimiliki. Jika ROA perusahaan meningkat maka laba perusahaan ikut bertambah dan berakibat pada ketertarikan investor dan akhirnya harga juga menanjak (Egam et al., 2017).

\section{Debt to Equity Ratio}

Untuk kepemilikan modal usaha, tak jarang pengusaha juga harus meminjam uang sebagai modal kepada pihak krrditor. Rasio yang dipakai untuk mengetahui modal perusahaan yang dijadikan sebagai jaminan atas utang yang dimiliki ialah Debt to equity Ratio (DER) (Julia \& Diyani, 2016). Tingginya nilai DER akan membuat pihak kreditor berpikir dua kali untuk meminjamkan dana kembali kepada perusahaan, karena semakin tinggi nilai DER sangat merugikan pihak krrditor seperti Bank (Rahmadewi \& Abundanti, 2018).

\section{Debt to Asset Ratio}

Rasio ini sebagai alat ukur perusahaan dalam menilai seberapa banyak aktiva perusahaan yang diperoleh melalui utang. Hal ini menandakan jika nilai Debt to Asset Ratio tinggi berarti aset perusahaan dimulai dengan untang yang tinggi pula. Dengan demikian, dituntut perusahaan agar dapat mengelola utang dengan baik agar dapat membayar utang-utang yang telah dipinjam untuk kepemilikan set perusahaan (Sutriani, 2014).

\section{Current Ratio}

Sebuah perusahaan tidak akan lepas dari kewajiban-kewajiban yang harus dipenuhi, salah satunya utang lancar jangka pendek yang lebih dikenal dengan kata Current Ratio (CR). CR dapat dijadikan gambaran atas tanggungjawab perusahaan terhadap investor karena dengan perusahaan dapat dengan tepat waktu dalam membayar untang jangka pendeknya berarti perusahaan dapat mengelola utang mereka dengan baik sehingga utang dapat berputar sesuai dengan kebutuhan perusahaan (Hanafi et al., 2016).

\section{Earning per Share}

Dengan penjualan saham perlembar juga mendukung untuk meningkatkan pendapatan perusahaan. Pendapatan bersih yang diperoleh terhadap jumlah lembar saham yang beredar disebut Earning per Share (EPS) (Hanafi et al., 2016). Sehingga dengan singkat dapat dijelaskan bahwa EPS yaitu total laba yang diperoleh dari penjualan saham per lembar.

\section{Hipotesis}

Hipotesa dalam penelitian ini adalah sebagai berikut:

H1 : Harga saham dipengaruhi oleh ROE

H2 : ROA berpengaruh terhadap harga saham

H3 : DER mempengaruhi harga saham

H4 : DAR mempengaruhi harga saham

H5 : CR mempengaruhi harga saham secara signifikan

H6 : EPS berpengaruh signifikan teradap harga saham

H7 : Secara simultan variabel independen berpengaruh terhadap harga saham 


\section{Metode Penelitian}

Penelitian ini penelitian kuantitatif yang mengolah data angka-angka perusahaan untuk mencapai kesimpulan atas permasalahan. Objeknya di Bursa Efek Indonesia (BEI) wilayah Kepri. Semua Perusahaan LQ45 yang terdaftar di Bursa Efek Indonesia (BEI) tahun 2014 sampai dengan 2018 dijadikan sebagai populasi. Untuk lebihmaksimal dalam penelitian maka dibutuhkan sampel yang representatie, maka sampel diambil melalui teknik berdasarkan kriteria-kriteria yang dianggap perlu oleh peneliti (Ghozali, 2013). Bagian pengolahan data menggunakan uji asumsi klasik, regresi linier berganda serta menggunakan uji hipotesis yang berupa uji parsial (t), uji simultan (f) dan uji koefisien determinasi (R2).

\section{Pembahasan}

\section{Uji Normalitas}

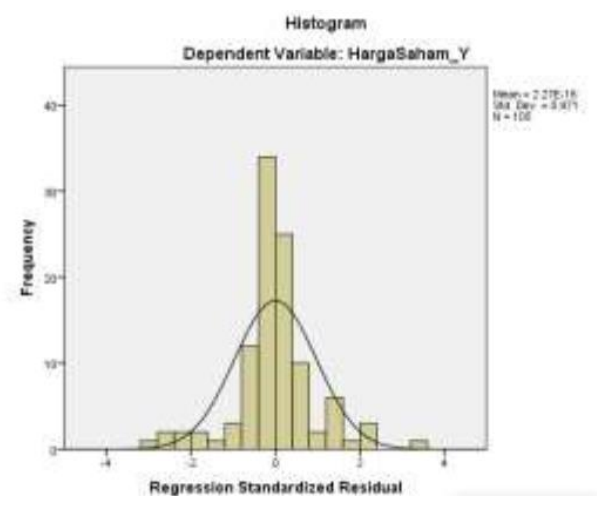

Gambar 1. Bell Shaped Curve

Berdasarkan gambar 1, dinyatakan bahwa data penelitian adalah normal.

\section{Uji Multikolinieritas}

Tabel 2

Multikolinieritas

\begin{tabular}{|c|c|c|c|}
\hline \multirow{2}{*}{\multicolumn{2}{|c|}{ Model }} & \multicolumn{2}{|c|}{ Colinearity Statistics } \\
\hline & & Tolerance & VIF \\
\hline \multicolumn{4}{|c|}{ (Constant) } \\
\hline & ROE_X1 & .438 & 2.284 \\
\hline \multirow{5}{*}{1} & ROE_X2 & .423 & 2.364 \\
\hline & DER_X3 & .585 & 1.710 \\
\hline & DAR X4 & .457 & 2.187 \\
\hline & $\mathrm{CR} \times \bar{X} 5$ & .674 & 1.483 \\
\hline & EPS_X6 & .940 & 1.063 \\
\hline
\end{tabular}

Diperoleh semua angka pada tolerance $>0,10$ dan semua nilai VIF $<10$ bertanda tidak terdapat multikolinieritas antar variabel.

\section{Uji heterokedastisitas}

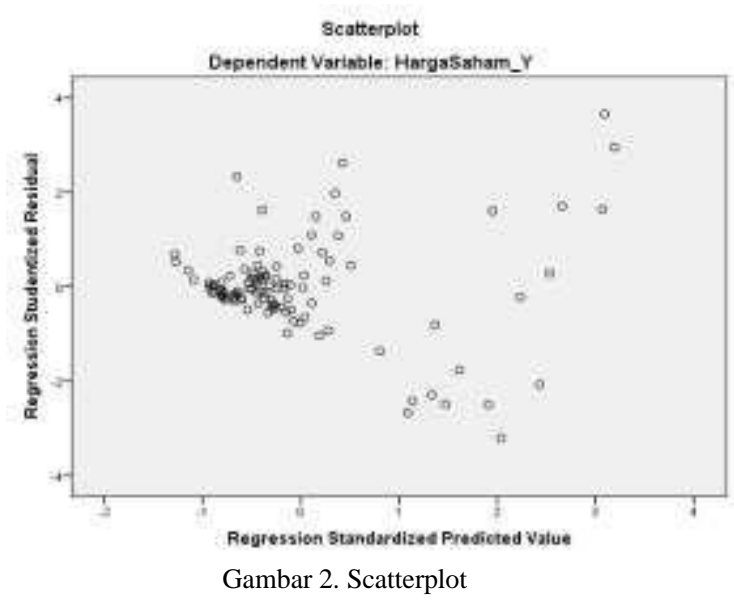

Gambar 2 menunjukkan titik-titik menyebar dan tidak hanya menumpuk pada satu titik yang berarti tidak mengandung heterokedastisitas di penelitian ini.

Uji Autokorelasi

Tabel 3

Autokorelasi

\begin{tabular}{lllll}
\hline Model & R & R Square & $\begin{array}{l}\text { Adjusted } \\
\text { R square }\end{array}$ & $\begin{array}{l}\text { Durbin } \\
\text { Watson }\end{array}$ \\
\hline 1 & $.748^{\mathrm{a}}$ & .560 & .533 & 1.808 \\
\hline
\end{tabular}

Diperoleh Nilai DU pada tabel $=1.8042$, maka 4 DU $=4-1.8042=2.1958$, sehingga $1.8042<1.808$ $<2.1958$, karena memenuhi ketentuan tersebut berarti hasilnya menunjukkan bahwa tidak terjadi autokorelasi.

Analisis Regresi Linier berganda

Tabel 4

\begin{tabular}{|c|c|c|c|c|}
\hline & \multirow{2}{*}{ Model } & \multicolumn{2}{|c|}{$\begin{array}{l}\text { Unstandardized } \\
\text { Coefficients }\end{array}$} & \multirow{2}{*}{$\begin{array}{c}\text { Standardized } \\
\text { Coefficients } \\
\text { Beta }\end{array}$} \\
\hline & & B & $\begin{array}{c}\text { Std. } \\
\text { Error }\end{array}$ & \\
\hline \multirow{7}{*}{1} & (Constant) & 713.777 & 3940.296 & \\
\hline & ROE_X1 & 210.123 & 61.665 & .345 \\
\hline & ROE_X2 & 33.421 & 109.078 & .032 \\
\hline & DER_X3 & 61.222 & 574.478 & .009 \\
\hline & DAR_X4 & -36.480 & 6812.722 & -.001 \\
\hline & CR_X 5 & -8.900 & 6.145 & -.118 \\
\hline & EPS_X6 & 8.304 & .965 & .595 \\
\hline
\end{tabular}


Melalui tabel 4, maka dapat dibentuk persamaan regresi linier berganda yaityu:

$\mathrm{Y}=713.777+210.123 \mathrm{X} 1+33.421 \mathrm{X} 2+61.222 \mathrm{X} 3-$ $36.480 \times 4-8.900 \times 5+8.304 X 6$

Uji Parsial ( $t)$

\begin{tabular}{llcc} 
& \multicolumn{3}{c}{ Tabel 5 } \\
Uji t & \\
\hline Model & $\mathbf{t}$ & Sig. \\
\hline & (Constant) & .181 & .857 \\
& ROE_X1 & 3.407 & .001 \\
& ROE_X2 & .306 & .760 \\
1 DER_X3 & .107 & .915 \\
& DAR_X4 & -.005 & .996 \\
& CR_X5 & -1.448 & .151 \\
& EPS_X6 & 8.606 & .000 \\
\hline & & $\mathbf{t}$ & Sig. \\
\hline & (Constant) & .181 & .857 \\
& ROE_X1 & 3.407 & .001 \\
& ROE_X2 & .306 & .760 \\
1 DER_X3 & .107 & .915 \\
& DAR_X4 & -.005 & .151 \\
& CR_X5 & -1.448 & .000 \\
\hline
\end{tabular}

Dijelaskan melalui tabel 4 bahwa ROE dan EPS memiliki nilai sig 0,001 dan $0,000<0,005$ berarti hipotesis 1 dan 6 diterima. Dan angka ROA, DER, DAR dan CR berturunt-turut 0,76; 0,915; 0, 996; dan 0,151 dimana semua angka $>0,05$ yang menandakan hipotesis 2,3,4, dan 5 ditolak.

\section{Uji Simultan $(F)$}

Pada tabel 6 dapat diamati nilai sig $0,000<0,005$ maka diambil keputusan hipotesis 7 diterima yang berarti variabel dependen dipengaruh variabel independen secara simultan.

\begin{tabular}{|c|c|c|c|}
\hline & \multicolumn{3}{|c|}{$\begin{array}{c}\text { Tabel } 6 \\
\text { Uji F }\end{array}$} \\
\hline & $\begin{array}{l}\text { Model } \\
\text { Regression }\end{array}$ & $\begin{array}{c}\mathbf{t} \\
20.788\end{array}$ & $\begin{array}{l}\text { Sig. } \\
.000^{\mathrm{b}}\end{array}$ \\
\hline 1 & $\begin{array}{l}\text { Residual } \\
\text { Total }\end{array}$ & & \\
\hline
\end{tabular}

\section{Uji Koefisien Determinasi $\left(R^{2}\right)$}

\begin{tabular}{cccc}
\multicolumn{5}{c}{ Tabel 7 } \\
Uji R $^{2}$ \\
Model & R & R Square & $\begin{array}{c}\text { Adjusted } \\
\text { R Square }\end{array}$ \\
1 & $.748^{\mathrm{a}}$ & .560 & .533 \\
\hline
\end{tabular}

Dilihat pada tabel 6, angka Adjusted R Square 0,533 yang berarti sumbangan pengaruh variabel independen sebanyak 53,3\% terhadap harga saham.

ROE berpengaruh signifikan terhadap harga saham

Jumlah laba bersih terhadap ekuitas atau modal perusahaan. Jika laba yang diperoleh lebih tinggi dibandingkan modal perusahaan akan mendatangkan keuntungan bagi perusahaan. Karena semakin banyak laba bersih yang diperoleh maka semakin banyak dana yang dimiki perusahaan dalam pengembangan perusahaan dan sisanya dapat dibagikan kepada para pemegang saham. Jika laba yang dibagikan kepada investor semakin besar, maka investor juga akan semakin senang dan lebih percaya lagi terhadap perusahaan dan tidak hanya itu bahkan calon investor pun akan semakin melirik perusahaan. Semakin banyak investor yang berniat membeli saham perusahaan akan berdampak positif yaitu kenaikan harga saham perusahaan. Penelitian ini didukung oleh penelitian Julia dan Diyani (2016), jika ROE berpengaruh terhadap harga saham.

ROA tidak berpengaruh signifikan terhadap harga saham

Pada hasil ini menyatakan bahwa aset yang tinggi tidak serta merta membuat peningkatan harga saham perusahaan. Hal ini dikarenakan sebagian investor tidak terlalu memperdulikan laba yang diperoleh melalui aset perusahaan, tetapi mereka hanya memperhitungkan jumlah pengembalian yang diperoleh apalagi bagi para investor yang bermain dalam investasi jangka pendek. Sehingga semakin tinggi laba yang diperoleh perusahaan melalui aset tidak sejalan dengan kenaikan harga saham yang signifikan dipasar modal. Penelitian dari Egam et al., (2017) juga setuju jika ROA tidak berpengaruh signifikan terhadap harga saham.

DER tidak berpengaruh signifikan terhadap harga saham

Jika hutang perusahaan terhadap kreditor lebih besar terhadap modal perusahaan, maka akan membuat para kreditor lebih teliti dalam memberikan utang terhadap perusahaan. Walaupun utang perusahaan meningkat dan dapat dikelola dengan baik untuk keberlangsungan perusahaan, maka hutang tersebut tidak akan mempengaruh mindset investor 
dalam kepemilikan saham perusahaan karena mereka beranggapan utang bukanlah masalah besar jika dapat dikelola dan dimanfaatkan untuk kepentingan perusahaan. Penelitian Damayanti dan Valianti (2016) juga sependapat bahwa DER tidak menunjukan pengaruh terhadap harga saham.

\section{CR tidak berpengaruh signifikan terhadap harga saham}

Hutang lancar atau biasa juga kita kenal dengan hutang jangka pendek perusahaan. Tak jarang semua perusahaan memiliki kewajiban hutang jangka pendek mereka. Tetapi hutang jangka pendek tidak menjadi masalah yang besar didalam perusahaan jika perusahaan dapat membayar setiap utang jang pandek mereka. Semakin tinggi nilai CR perusahaan tidak mengikuti penurunan harga saham pula. Karena hutang lancar yang dapat dibayar tepat waktu tidak membuat para investor mengurukan nilat untuk memiliki saham perusahaan sehingga saham perusahaan tetap stabil didalam pasar modal. Azmi et al., (2016) menyatakan bahwa harga saham tidak dipengaruhi oleh CR.

\section{EPS berpengaruh signifikan terhadap harga saham}

Semakin banyak laba yang didapatkan perusahaan melalui penjualan saham yang beredar dipasar modal akan dapat meningkatkan kegiatan perusahaan sehingga laba perusahaan semakin meningkat dan pembagian dividen kepada para investor juga akan semakin besar. Hal ini membuat para investor semakin nyaman dan meningkatkan jumlah sahamnya dalam perusahaan yang berujung pada peningkatan harga saham perusahaan. Dukungan diperoleh dari penelitian Rahmadewi dan Abundanti (2018) yang mengatakan harga saham dipengaruhi oleh EPS.

Secara simultan keseluruhan variabel independen berpengaruh terhadap harga saham

Jika profitabilitas (ROE, ROA) meningkat dan peruahaan dapat membayar utang (DER, DAR, CR) baik jangka panjang dan jangka pendek tepat waktu ditambah lagi dengan peningkatan laba melalui penjualan harga lembar saham perusahaan, maka perusahaan akan dapat berkembang dengan baik sehingga banyak para investor tertarik untuk berinvestasi yang berakhir dengan meningkatnya harga saham perusahaan.

\section{Kesimpulan}

Akhir dari sebuah penelitian adalah hasil dari yang diperoleh melalui pengolahan data yang telah dilakukan. Secara singkat hasil inti penelitian ini dapat diambil kesimpulan sebagai berikut:

1. ROA dan EPS secara parsial berpengaruh signifikan terhadap harga saham.

2. ROE, DAR, DER, CR secara parsial tidak berpengaruh terhadap harga saham.

3. Secara keseluruhan variabel independen yang ada berpengaruh signifikan terhadap harga saham

4. Dan terakhir diperoleh sumbangsi pengaruh varibael independen terhadap harga saham sebesar 53,3\%.

Berdasarkan kesimpulan penelitian diatas, berikut saran yang dapat diberikan, antara lain, yaitu.

1. Peneliti selanjutnya diharapkan menambah variabel penelitian, agar dapat diketahui adanya variabel lain yang mempengaruhi harga saham perusahaan.

2. Bagi para investor disarankan sebelum membeli saham perusahaan agar memperhatikan laporan keuangan perusahaan terutama rasio fundamental perusahaan agar pengembalian yang diharapkan ats dana yang ditanamkan dapat diperoleh sesuai dengan keinginan investor.

\section{Referensi}

Anisa, N. (2015). Analisis Faktor-Faktor Yang Mempengaruhi Return Saham (Studi Kasus Pada Perusahaan Sub Sektor Automotive and Components yang Terdaftar Di Bursa Efek Indonesia Periode 2010-2014). Perbanas, 1(1), 72-86.

Artha, D. R., Achsani, N. A., \& Sasongko, H. (2014). Analisis Fundamental, Teknikal Dan Makroekonomi Harga Saham Sektor Pertanian. Jurnal Manajemen Dan Kewirausahaan, 16(2), 175-183. https://doi.org/10.9744/jmk.16.2.175

Azmi, M. U., Andini, R., \& Raharjo, K. (2016). Analisis Pengaruh Net Profit Margin (NPM), Return on Assets (ROA) Dan Current Ratio (CR) Terhadap Harga Saham Emiten LQ45 Yang Terdaftar Di Bursa Efek Indonesia Pada Tahun 2010-2014. Journal of Accounting, 2(2).

Damayanti, R., \& Valianti, R. M. (2016). Pengaruh Debt to Assets Ratio, Debt to Equity Ratio, Return on Assets dan Net Profit Margin terhadap Harga Saham Pada Perusahaan Indeks LQ-45 Di Bursa Efek Indonesia. In Jurnal media Wahana Ekonomika (pp. 1636).

Egam, G. E. Y., Ilat, V., \& Pangerapan, S. (2017). Pengaruh Return on Asset (ROA), Return on Equity (ROE), Net Profit Margin (NPM), dan Earning per Share (EPS) Terhadap Harga Saham Perusahaan Yang Tergabung Dalam Indeks Lq45 Di Bursa Efek Indonesia Periode Tahun 2013-2015. Jurnal EMBA, 5(1), 105-114. 
Ghozali, I. (2013). Aplikasi Analisis Multivariate Dengan Program IBM SPSS 21. Badan Penerbit Universitas Ponogoro.

Hanafi, M, M., \& Halim, A. (2016). Analisis Laporan Keuangan (Kelima). UPP STIM YKPN. Jiwandono, T. (2014). Analisis Faktor Fundamental Terhadap Harga Saham Sektor Perbankan Yang Go Public Di Indeks Kompas 100. Jurnal Ilmu Manajemen, 2, 783-794.

Julia, T. T., \& Diyani, L. A. (2016). Pengaruh Faktor Fundamental Keuangan dan Makro Ekonomi terhadap Harga Saham. Jurnal Bisnis Dan Komunikasi, 2, 109-119.
Rahmadewi, P. W., \& Abundanti, N. (2018). Pengaruh EPS, PER, $\mathrm{CR}$ dan ROE terhadap harga saham di Bursa Efek Indonesia. EJurnal Manajemen Universitas Udayana, 7(4).

Suselo, D., Djazuli, A., \& Indrawati, N. K. (2015). Pengaruh Variabel Fundamental dan Makro Ekonomi terhadap Harga saham (Studi pada perusahaan yang masuk dalam Indeks LQ45). Jurnal Aplikasi Manajemen, 13(1), 104-116.

Sutriani, A. (2014). Pengaruh profitabilitas, leverage, dan likuiditas terhadap return saham dengan nilai tukar sebagai variabel moderasi pada saham LQ-45. Journal of Business and Banking, 4(1), 67-80. 